\title{
PANORAMA DOS RECURSOS HÍDRICOS NO MUNDO E NO BRASIL
}

\author{
Tatiana Dias Cantelle* \\ Eudes de Castro Lima** \\ Luís Antônio Coimbra Borges ${ }^{* * *}$
}

RESUMO: A importância da água como um recurso essencial à vida é incontestável. Por essa razão, objetivou-se com este estudo avaliar a água mediante a análise de sua conexão com diferentes aspectos, sendo eles: produção de alimentos, energia, indústria, acesso à água potável e saneamento, consumo e crescimento populacional, manutenção de ecossistemas, sustentabilidade hídrica, incluindo inovações tecnológicas e perspectivas. Dessa forma, a compreensão do panorama dos recursos hídricos é elucidada sob diferentes concepções no âmbito global e nacional, por meio de revisão bibliográfica. Os resultados indicam que a seca e a escassez hídrica continuarão representando um grande desafio aos governos e população, assim como a crescente competição, entre os diferentes setores da sociedade, pelo uso da água. A gravidade da situação ainda permanece latente, o que reforça a necessidade de acesso à informação e implementação de novas formas de gestão dos recursos hídricos, em prol da segurança hídrica.

PALAVRAS-CHAVE: Água; Crise hídrica; Desenvolvimento sustentável; Irrigação.

\section{SURVEY OF HYDRIC RESOURCES WORLDWIDE AND IN BRAZIL}

\begin{abstract}
The importance of water as an essential resource for life is a fact. Current study evaluates water through an investigation of its link with different aspects: production of food, energy, industry, access to drinkable water and drainage, consumption, population growth, maintenance of ecosystems, water sustainability, including technological innovations and perspectives. Survey of hydric resources is elucidated under different conceptions within the national and worldwide environ-

\footnotetext{
Mestre em Administração e em Tecnologias e Inovações Ambientais pela Universidade Federal de Lavras (UFLA), Brasil. E-mail: taticantelle@gmail.com

** Mestre em Ciência da Computação pela Universidade Federal de Lavras (UFLA), Brasil.

*** Doutorado em Engenharia Florestal também pela Universidade Federal de Lavras (UFLA), Docente no Departamento de Ciências Florestais na Universidade Federal de Lavras (UFLA), Brasil.
} 
ment through a bibliographic review. Results show that drought and hydric scarcity, increasing competition on the use of water between different segments of society are a great challenge to governments and population. The seriousness of the situation is still latent. Access to information and implementation of new types of management of hydric resources are required for hydric safety.

KEY WORDS: Water; Hydric crisis; Sustainable development; Irrigation.

\section{INTRODUÇÃO}

A água é um bem ambiental essencial à vida e a partir do momento em que se agrega a ela valor econômico passa a ser denominada como recurso hídrico. Esses recursos hídricos encontram-se sob pressão de diversos fatores, dentre eles, a crescente população mundial.

Estima-se que para suprir a demanda de mais dois bilhões de pessoas até 2050 a economia mundial deverá crescer quatro vezes, com acréscimo da demanda por recursos naturais e energia, que deve atingir um patamar $80 \%$ maior. Cerca de $70 \%$ da população mundial viverá em áreas urbanas e para alimentar a população crescente, com mudanças de preferências alimentares, há projeção de expansão global das terras agrícolas na próxima década (OECD, 2012). O Brasil, no contexto mundial, destaca-se como um país com a quinta maior população, a quinta maior área superficial e como uma das dez maiores economias mundiais. Em termos hidrológicos, o país foi contemplado com 12\% das reservas de água doce e algumas das maiores bacias hidrográficas do mundo (OECD/FAO, 2015).

$\mathrm{O}$ crescimento populacional, aliado à intensa urbanização, amplia as demandas dos setores agrícola, industrial e energético, podendo estas serem incrementadas segundo os padrões de consumo vigentes. Em virtude do aumento da produção de alimentos e bens de consumo, recursos naturais são explorados, impactando os ecossistemas locais mediante a poluição e degradação, comprometendo a sustentabilidade e promovendo alterações climáticas. Neste cenário, a quantidade e a qualidade da água ficam comprometidas, ocasionando áreas de escassez hídrica. Essa concepção conduz o planeta para uma possível crise hídrica mundial e 
centraliza a água, como objeto de grandes discussões no que concerne ao seu papel no desenvolvimento sustentável.

Assim sendo, este estudo procura fazer um balanço das ações passadas, dos desafios do presente e das futuras oportunidades, a fim de fornecer informações confiáveis que podem suscitar reflexões sobre a forma como utilizamos a água. A problematização concentra-se em responder quais as conexões existentes, no âmbito global e nacional, entre os recursos hídricos e questões como: alimentação e agropecuária, energia, indústria, população, consumo, ecossistema, sustentabilidade, inovação tecnológica e perspectivas.

Para isso, fez-se uso da metodologia de revisão bibliográfica que representa um resumo da literatura recente. Para Pautasso (2013) revisar a literatura requer a capacidade de lidar com várias tarefas, como: encontrar e avaliar o material relevante, sintetizar informações de várias fontes e parafrasear o pensamento crítico. Embora o reconhecimento para os cientistas venha principalmente de pesquisa primária, as revisões de literatura são oportunas pois podem levar a novas descobertas, além de serem amplamente lidas. Assim, a relevância deste estudo se justifica pela possibilidade de ampliação do conhecimento sobre os recursos hídricos.

\section{CONJUNTURA DOS RECURSOS HÍDRICOS}

A água é o motor do desenvolvimento econômico e social: é vital para manter a saúde, a produção de alimentos, a geração de energia, gerenciar o meio ambiente e criar empregos (WORLD BANK, 2016). Neste sentido, elucida-se o percurso hidrológico, desde a captação, passando pelos vários usos e o retorno para o ambiente natural.

Esta seção reúne os principais tópicos abordados pelas organizações mundiais e nacionais no tocante aos recursos hídricos.

\section{1 ÁGUA, ALIMENTO E AGROPECUÁRIA}

A conexão entre água e alimento é simples, a agricultura e pecuária necessitam de água para sustentar a produção. Produção essa, crescente, assim como a 
população mundial (WWAP, 2012). Estima-se por ano, a produção de 8,4 bilhões de toneladas de alimentos, valor que deve atingir 13,5 bilhões de toneladas para sustentar a população mundial projetada para 2050 (FAO, 2014). Aliado a essa constatação, observa-se a mudança do padrão alimentar, com o aumento do consumo de carne e produtos lácteos, causando um maior impacto sobre o consumo de água ao longo dos últimos 30 anos, com probabilidade de continuar até meados do século XXI (WWAP, 2012).

O setor agrícola tem um papel importante na sustentação do desempenho econômico e na contribuição para a balança comercial do Brasil. A agricultura brasileira cresceu fortemente durante as últimas três décadas. A produção agrícola total mais do que duplicou em volume em relação ao seu nível em 1990 e a produção de gado quase triplicou, principalmente com base em melhorias de produtividade (OECD/FAO, 2015). O crescimento da produção nos próximos dez anos é estimado em 255,3 milhões de toneladas de grãos (acréscimo de 30\% da produção atual) e 34.123 milhões de toneladas de carne, incluindo bovina, suína e aves (acréscimo de 29,8\%). Esse incremento deve continuar acontecendo com base na produtividade, visto que para a produção está previsto o crescimento de 30\% e para a área plantada, 12,7\% (MAPA, 2016).

A intensificação agrícola tem como tendência a irrigação cuja área global de cultivo equipada continua a se expandir a uma taxa de $0,6 \%$ ao ano. A utilização de águas subterrâneas na irrigação também se expande rapidamente, atingindo 38\% da água utilizada nas áreas irrigadas (FAO, 2011). Dada a abundância de recursos hídricos, a importância da irrigação no Brasil é pequena, com apenas cerca de $2 \%$ da superfície agrícola equipada com irrigação. Esta ação, no entanto, tem-se ampliado desde 1990, com a agricultura fazendo atualmente quase $60 \%$ das retiradas anuais de água doce (OECD/FAO, 2015). A área irrigada em 2014 foi estimada em 6,11 milhões de hectares ou 21\% do potencial nacional, que corresponde a 29,6 milhões de hectares. Observa-se que o expressivo aumento da agricultura irrigada cresce a taxas superiores às do crescimento da área plantada total. Nos últimos anos, destacaram-se os métodos de irrigação localizada e por pivô central (ANA, 2015).

$\mathrm{O}$ uso de água para irrigação de culturas pode promover a produção de alimentos, mas também pode reduzir o fluxo dos rios e potencial hidroelétrico (WWAP, 2014). Ademais, a aplicação de agroquímicos, dentro e fora das áreas de ir- 
rigação, tem degradado o solo e poluído cursos de água, aquíferos e zonas costeiras (WORLD BANK, 2016).

Sob esse contexto, grandes mudanças são necessárias, na política e na gestão, em toda a cadeia de produção agrícola, visando assegurar a melhor utilização dos recursos hídricos disponíveis (WWAP, 2012). Ao nível das explorações agrícolas, os agricultores podem mudar para culturas menos exigentes em água e utilizar técnicas de cultivo diferentes, para gerar mais valor a partir da água e outros insumos à sua disposição (WORLD BANK, 2016), assegurando os recursos hídricos, fator chave para a segurança alimentar (WWAP, 2012).

\section{2 ÁGUA E ENERGIA}

Água, alimento e energia são indissociáveis. Enquanto a água é um insumo para a produção de bens ao longo de toda a cadeia de abastecimento agroalimentar, a energia é necessária para produzir e distribuir água e alimentos (WWAP, 2014). Além disso, tem-se a bioenergia, que representa cerca de $10 \%$ do consumo mundial de energia. A bioenergia começou a competir com a produção de alimentos, por recursos como terra e água, e esta competição é susceptível de aumentar os preços mundiais de alimentos (FAO, 2011), elevando também a demanda por recursos hídricos (WWAP, 2014). No Brasil, a agricultura é um importante contribuinte para o fornecimento de energia, principalmente no que se refere à biomassa da cana (OECD/FAO, 2015).

Em termos de produção de energia renovável, a hidroeletricidade representa um quinto da produção mundial (WORLD BANK, 2016). Nos últimos 30 anos, a oferta primária de energia hidráulica no mundo evoluiu concentradamente em duas regiões: Ásia, com destaque para a China, e América Latina, com destaque para o Brasil (BRASIL/MME, 2007), onde a principal fonte de geração de energia elétrica é hidráulica, que responde a $65,2 \%$ da oferta interna, embora tal fonte tenha apresentado uma redução de 4,5\% na comparação com o ano anterior (EPE, 2015). A capacidade instalada de energia hidroelétrica brasileira, em dezembro de 2014, encontrava-se distribuída em 1.154 empreendimentos hidroelétricos, sendo 484 Centrais de Geração Hidrelétrica (CGHs), 470 Pequenas Centrais Hidrelétricas (PCHs) e 200 Usinas Hidrelétricas (UHEs) (ANA, 2015). 
Em 2014, a expansão da capacidade instalada no Brasil foi impulsionada pelas centrais hidráulicas, que contribuíram com 44,3\% (EPE, 2015). Todavia, segundo a publicação do Ministério de Minas e Energia (2007), vários desafios têm sido colocados para incremento da expansão hidroelétrica. Dentre eles, os prazos para obtenção das licenças ambientais e os impactos ambientais e sociais gerados. O Brasil, detentor de um dos maiores potenciais do planeta, possui dois terços do território nacional coberto por dois biomas de alto interesse do ponto de vista ambiental, como o são a Amazônia e o Cerrado, e 70\% do potencial hidroelétrico brasileiro a aproveitar localizam-se nesses biomas, portanto, pode-se antever grandes dificuldades para a expansão da oferta hidroelétrica (BRASIL/MME, 2007). Apesar do uso de água para a geração hidroelétrica ser considerado não consuntivo, ou seja, não há consumo da água captada no processo produtivo, pode existir ou não a derivação das águas de seu curso natural, a fim de possibilitar o seu uso. Além disso, o retorno das águas ocorre, sempre, com menor vazão ou com alteração na sua qualidade (ANA, 2013).

Neste contexto, a água é cada vez mais importante enquanto critério de avaliação da viabilidade dos projetos de energia, à medida que o crescimento da população e da economia intensificam a competição por recursos hídricos (IEA, 2012). Ao passo que, o desenvolvimento de energia hidroelétrica oferece grandes oportunidades, ele também vem com desafios complexos e riscos, que variam de forma significativa pelo tipo, local e escala de projetos. Fatores como o reassentamento de comunidades, a inundação de grandes áreas e mudanças significativas para os ecossistemas fluviais devem ser cuidadosamente considerados. Dessa forma, será possível mitigar os riscos e compartilhar melhor os benefícios deste recurso renovável (WORLD BANK, 2016). Por fim, para fazer face às vulnerabilidades da água no setor de energia, será necessário aplicar melhores tecnologias e uma maior integração das políticas no domínio energético e hídrico (IEA, 2012).

\section{3 ÁGUA E INDÚSTRIA}

Assim como para a produção de alimentos, a água e a energia são fatores essenciais para a produção industrial, que busca alcançar eficiência hídrica e energé- 
tica, com base em relações de custo-benefício (WWAP, 2014). A indústria utiliza os recursos hídricos em quantidades significativas de muitas maneiras diferentes: como água de processo para refrigeração, alimentação de caldeira, agente, solvente de limpeza ou descarga de resíduos (WINTGENS; LI; KAZNER, 2013).

Proporcionalmente, o setor industrial utiliza mais recursos energéticos do que hídricos. Todavia, pouco se sabe sobre a quantidade real de água que é retirada e consumida pela indústria em suas necessidades de fabricação, de transformação e de produção. Dados indicam que o percentual de água necessária pelo setor industrial de um país é geralmente proporcional ao nível de renda média. Isso representa, apenas, cerca de 5\% das retiradas de água em países de baixa renda, em comparação com mais de 40\%, em alguns países de alta renda. Esta observação sugere que 0 nível de desenvolvimento econômico de um país ou região é um importante motor do uso de água na indústria, e pode vir a ter tanta influência sobre a utilização desse recurso, como o crescimento populacional (WWAP, 2012).

Embora a água seja muitas vezes o único grande fluxo de massa em várias indústrias de processo com abastecimento de água e de descarga de águas residuais, a importância econômica da gestão da água industrial é, muitas vezes, considerada inferior em comparação com outros recursos. A produção de efluentes altamente tóxicos, que impactam fortemente os recursos hídricos caso não tratados adequadamente provocaram situações desastrosas em todo o mundo (WINTGENS; LI; KAZNER, 2013). Por essa razão, no Brasil há regulamentações que definem condições e padrões de lançamento de efluentes em corpos de água.

Com vistas à tecnologia industrial, à compreensão do papel essencial da água na economia e às pressões ambientais colocadas sobre esse recurso, o setor industrial busca por medidas para reduzir seu consumo de água por unidade produzida, melhorando assim, a produtividade da água industrial. Também atentam-se para a qualidade da água, especialmente a jusante, esforçam-se na reutilização e reciclagem de água, combinando a qualidade da água ao uso previsto, deslocando-se para uma produção mais limpa (WWAP, 2016). Essas e outras ações promovem a sustentabilidade ambiental, um dos Objetivos do Desenvolvimento Sustentável (ODS), especificamente o nono, a ser alcançado mediante a dissociação da prosperidade gerada por atividades industriais a partir do uso excessivo dos recursos naturais e impacto ambiental negativo (UNIDO, 2015). 
2.4 ÁGUA E POPULAÇÃO

$\mathrm{O}$ acesso à água, para sobrevivência, é uma necessidade humana básica e um direito humano fundamental (UNDP, 2006). Por essa razão, os Objetivos de Desenvolvimento do Milênio (ODM) estabeleceram como meta reduzir, até 2015, a proporção da população sem acesso permanente e sustentável à água potável segura e esgotamento sanitário. As projeções, para o período de 25 anos (1990-2015), estabeleciam metas que almejavam atender $88 \%$ e $77 \%$ da população mundial, nos aspectos de acesso à água potável e saneamento básico, respectivamente. A meta global dos ODM para a água potável foi atingida em 2010 e, em 2015, o percentual chegou a 91\% da população mundial, ou seja, 2,6 bilhões de pessoas passaram a ter acesso à água potável desde 1990. Contudo, a meta para saneamento básico não foi alcançada, abrangendo apenas $68 \%$ da população mundial em 2015 , o que representa mais 2,1 bilhões de pessoas com acesso ao serviço de saneamento básico desde 1990 (UNITED NATIONS, 2015).

Apesar dos avanços observados, atualmente, 663 milhões de pessoas ainda não têm acesso a fontes de água potável e a 2,4 bilhões de pessoas é negado o acesso ao saneamento básico adequado. Países menos desenvolvidos não cumpriram as metas, mas houve um acréscimo da população atendida. Além do mais, diferenças de acesso entre as populações urbanas e rurais foram constatadas, com 96\% e 82\% da população urbana mundial, em comparação com $84 \%$ e $51 \%$ da população rural, com acesso a fontes de água potável e instalações sanitárias melhoradas, respectivamente (FUNDO DAS NAÇÕES UNIDAS PARA A INFÂNCIA, 2015).

O Brasil alcançou as metas dos ODM relativas ao abastecimento de água e ultrapassou a média mundial no que se refere ao esgotamento sanitário. Conforme a ODMBrasil (2016) o país está em direção à universalização do acesso ao abastecimento de água no meio urbano, com aproximadamente 91,9\% dos domicílios ligados à rede de abastecimento. Se considerar o abastecimento de água por poço, a cobertura é de aproximadamente 97,4\%. No entanto, para o esgotamento sanitário, o percentual de domicílios ligados à rede coletora ou à solução individual por fossa séptica é de $75,3 \%$.

O acesso à água potável e serviços de saneamento adequados são vitais para a saúde humana, mas existem outros benefícios importantes, que vão desde o facil- 
mente identificável e quantificável (custos evitados, economia de tempo), ao mais intangível (conforto, bem-estar, a dignidade, a privacidade e segurança) (WWAP, 2009).

\section{5 ÁGUA E CONSUMO}

O crescimento populacional, a urbanização, a migração e industrialização, juntamente com o aumento da produção e do consumo, têm gerado crescentes demandas sobre os recursos hídricos (WWAP, 2015). A população mundial aumentou 4,4 vezes ao longo do século passado, enquanto a retirada de água aumentou 7,3 vezes, em relação ao mesmo período. Assim sendo, a retirada global de água aumentou 1,7 vezes mais rápido do que a população mundial. No entanto, a população mundial cresce a taxas exponenciais, ao passo que o aumento da captação de água diminuiu ao longo das últimas décadas (FAO, 2016).

Segundo a Organização das Nações Unidas para Agricultura e Alimentação (FAO, 2011), alimentar uma população em crescimento e com dieta mais diversificada vai aumentar a pressão do setor agropecuário sobre os recursos hídricos, tendo como base a média de produção anual (FAO, 2011). Ademais, mundialmente está previsto o aumento de $85 \%$ do consumo de água até 2035, o que se traduz em um movimento para a geração de eletricidade com utilização intensiva de água, bem como a expansão da produção de biocombustíveis (IEA, 2012).

De acordo com World Water Assessment Programme (WWAP, 2014), os dados sobre o uso da água (retiradas e consumo) e qualidade são muitas vezes ultrapassados, limitados ou inexistentes. Porém, é possível afirmar que a agricultura representa o setor com maior retirada de água a nível mundial, cerca de 70\% do total (WWAP, 2012, 2014). Conforme dados obtidos pelo sistema FAO AQUASTAT, em 2015, os índices globais de retirada de água correspondem a 69\% agrícola (incluindo irrigação, pecuária e aquicultura), 12\% municipal (incluindo domésticos) e 19\% industrial. Esses números, no entanto, são fortemente influenciados pelos poucos países que têm retiradas de água muito elevada. Portanto, com uma média das proporções de cada país, encontram-se, "para qualquer país", índices de 59, 23 e $18 \%$, respectivamente. Baseando-se ainda em informações desse sistema, o rateio 
de retirada de água tem forte variação entre as regiões e a importância da retirada da água na agricultura é altamente dependente do clima e da relevância do setor agrícola na economia (FAO, 2016).

O Brasil está projetado para manter o seu papel como um dos principais fornecedores para os mercados alimentares e agrícolas internacionais durante a próxima década e, ao mesmo tempo, atender às necessidades de uma demanda interna crescente (OECD/FAO, 2015). Este fato confirma a preponderância do setor de irrigação como o principal responsável pela vazão de retirada, que corresponde a $55 \%$ do total, seguido das vazões para fins de abastecimento humano urbano (22\%), industrial (15\%), animal (6\%) e abastecimento humano rural (2\%) totalizando uma demanda consuntiva de $2.275,07 \mathrm{~m}^{3} / \mathrm{s}$. Ao considerar a vazão efetivamente consumida o valor total é de $1.209,64 \mathrm{~m}^{3} / \mathrm{s}$, dos quais $75 \%$ correspondem a irrigação, 9\% animal, $8 \%$ abastecimento humano urbano, 6\% indústria e $2 \%$ abastecimento humano rural (ANA, 2015). Resultados que corroboram a relevância dos setores da economia nacional.

\section{6 ÁGUA E ECOSSISTEMA}

Os ecossistemas são uma fonte de grande riqueza (UNDP, 2006) e estão no centro do ciclo hidrológico global. Esse ciclo biogeoquímico é essencial para se alcançar uma gestão sustentável da água, que também se vincula ao funcionamento saudável dos ecossistemas (WWAP, 2012). A saúde do ecossistema depende de fluxos ambientais que garantem a distribuição sustentável e equitativa e o acesso à água e aos serviços ecossistêmicos relacionados. A qualidade, quantidade e os fluxos de água são essenciais para a manutenção das funções, processos e resiliência dos ecossistemas aquáticos, dos quais a subsistência e oportunidades econômicas dependem (WWAP, 2016). Neste contexto, Boelee (2011) destaca que a água desempenha um papel em todas as categorias de serviços ecossistêmicos, fornecendo serviços de provisão (água para uso consuntivo, não consuntivo e ambiente aquático), regulatórios (manutenção da qualidade da água, regulação climática e tamponamento), culturais (recreação, turismo e espiritual) e de suporte (reciclagem de nutrientes, mitigação das mudanças climáticas e resiliência ecossistêmica). 
A importância do ambiente aquático para a biodiversidade e para os serviços ecossistêmicos é inquestionável e, não há dúvida, que a água é um componente importante do meio ambiente e precisa ser tratada como tal (OECD, 2015). Historicamente, a concorrência entre os usuários de água é consagrada, especialmente a concorrência entre a água captada para o bem-estar humano direto e a água necessária para sustentar os vários serviços ecossistêmicos dela dependentes. Contudo, com crescimento populacional e a crescente demanda de água per capita, muitas vezes não há água de qualidade suficiente para a manutenção dos ecossistemas, que por não receberem fluxos ambientais adequados começam a se degradar e perder os serviços ecossistêmicos associados (BOELEE, 2011).

A integridade e funcionalidade desses ativos naturais vitais estão cada vez mais comprometidas. Aproximadamente 60 a 70\% dos ecossistemas mundiais estão sendo degradados a taxas superiores à sua capacidade de recuperação (WORLD BANK, 2016). Entre 2000 e 2010, foram perdidos cerca de 13 milhões de hectares de floresta em todo o mundo, quer através da devastação por causas naturais ou porque as terras foram convertidas para outros usos (UNITED NATIONS, 2015).

Com recursos de água doce abundantes, o Brasil detém uma das maiores bacias hidrográficas do mundo e ainda conta com $8.400 \mathrm{~km}$ de litoral (OECD/FAO, 2015). Em média, passam no território brasileiro cerca de $260.000 \mathrm{~m}^{3} / \mathrm{s}$, dos quais $205.000 \mathrm{~m}^{3} / \mathrm{s}$ estão na bacia do rio Amazonas (ANA, 2015). Ademais, o país contém a maior parte da biodiversidade terrestre do mundo, concentradas em seus biomas (floresta amazônica, caatinga, cerrado, pantanal, mata atlântica, campos sulinos, zona costeira e marinha). Apesar disso, o desmatamento se mantém significativo, reduzindo de 68\% para 61\% a cobertura nativa entre 1990 e 2011. A Amazônia legal, por exemplo, somou 75 milhões de hectares desmatados em 2010 (OEDC/FAO, 2015).

A conservação e a valorização dos ecossistemas hídricos são a única garantia de haver água para todos os usos necessários a longo prazo (OECD, 2015). Pensando nisso, a WWAP (2016) inclui os ecossistemas como parte do desafio do crescimento sustentável, devendo ser levado em conta nos contextos políticos e de tomada de decisão, para garantir a participação equitativa dos benefícios e contribuir para a redução da pobreza, especialmente nos países em desenvolvimento. 
A este respeito, o mercado emergente de mecanismos de Pagamento por Serviços Ambientais (PSA) pode oferecer, a populações de baixa renda, oportunidades de criar um novo tipo de empreendedorismo e, assim, incrementar a renda, enquanto implementam práticas de restauração e, ou, conservação (WWAP, 2016). Exemplos de práticas conservacionistas podem ser constatadas no Brasil, como o Programa Produtor de Água, implementado em Extrema, Minas Gerais, um esforço para melhorar a qualidade da água do rio Paraná e ao mesmo tempo proteger a biodiversidade da Mata Atlântica. O programa propõe a utilização de uma parte das taxas de água coletadas para pagar agricultores e pecuaristas que devem reflorestar áreas de preservação permanente em sua propriedade, as quais são essenciais para a manutenção dos serviços de regulação do rio Paraná. Os proprietários de terras também recebem assistência técnica para reflorestamento, conservação do solo e prevenção à erosão. Deste modo, o PSA pode desencadear a criatividade na busca de soluções inovadoras (BOELEE, 2011).

\section{7 ÁGUA E SUSTENTABILIDADE}

Acredita-se que, globalmente, há água suficiente disponível para as necessidades futuras, porém esta visão de mundo esconde grandes áreas de escassez hídrica absoluta que afeta bilhões de pessoas, muitas das quais são desfavorecidas economicamente (WORLD BANK, 2016). Dessa forma a sustentabilidade hídrica é questionada, em função da quantidade e qualidade, pois ambas são importantes para satisfazer as necessidades ambientais e humana (WWAP, 2012).

Ao retratar tais assuntos, um grupo de conceitos merece atenção, sendo eles os de vulnerabilidade, stress e escassez hídrica. A diferenciação é baseada em métodos hidrológicos, nos quais são estabelecidas diretrizes e faixas de classificação distintas. Segundo Grafton et al. (2014), os mais comumente empregados são: o indicador de Falkenmark (ou Índice de Estresse Hídrico), o Índice de Criticidade, o método da IWMI (International Water Management Institute) e o Índice de Pobreza Hídrica. Todos possuem limitações analíticas ao desconsiderarem fatores externos que impactam o acesso à água.

Para o Índice de Estresse Hídrico, por exemplo, a escassez de água é definida em termos do total de recursos hídricos disponíveis para a população de uma 
região, ou seja, a quantidade de água doce renovável disponível para cada pessoa, a cada ano. Assim, uma área é classificada em vulnerabilidade hídrica quando o abastecimento de água anual estiver abaixo de 2.500 metros cúbicos, por pessoa, por ano (m3/pessoa/ano); estresse hídrico, quando estiver abaixo de $1.700 \mathrm{~m} 3$; abaixo de 1000 m3 é dito que está enfrentando escassez de água; e abaixo de $500 \mathrm{~m} 3$, uma escassez de água absoluta (UNDP, 2006; WWAP, 2012).

Sabe-se que existem várias maneiras de definir a escassez de água, mas é necessário delimitar em linhas gerais essa concepção. Em geral, a escassez de água é definida como o ponto em que o impacto agregado de todos os usuários colide com o fornecimento ou a qualidade da água em um determinado país, na medida em que a demanda por todos os setores, incluindo o meio ambiente, não pode ser plenamente satisfeita (FAO, 2012). A escassez hídrica é uma função da oferta e da demanda, podendo ser física, econômica ou institucional e flutuar ao longo do tempo e do espaço (UNDP, 2006), sendo sinalizada por demandas insatisfeitas, tensão entre os usuários, competição por água, excesso de extração de água subterrânea e fluxos insuficientes para o ambiente natural (FAO, 2012).

A escassez hídrica afeta mais de $40 \%$ das pessoas em todo o mundo, um número alarmante que deverá crescer com o aumento das temperaturas globais, como consequência das mudanças climáticas. A diminuição dos suprimentos de água potável é um problema grave que está impactando todos os continentes. Em 2011, 41 países sofreram estresse hídrico, dez deles estão perto de esgotar a sua oferta de água doce renovável e agora deve recorrer a fontes não convencionais (UNDP, 2015). Esta progressiva escassez hídrica induz a competição pela água entre os usuários, entre os setores da economia, e entre países e regiões que partilham um recurso comum, como é o caso dos rios internacionais (UN WATER, 2007). Outro aspecto a ser considerado refere-se à qualidade da água, que está se tornando uma crescente preocupação global, com os riscos de degradação causando impactos econômicos e sociais diretos. Embora existam alguns casos de sucessos regionais na melhoria da qualidade da água, não há dados que sugiram uma melhora da qualidade da água em uma escala global (WWAP, 2012).

Sob essas ponderações, destaca-se o Nordeste brasileiro cuja população convive com a seca que já destruiu grandes áreas de terras agrícolas, afetando cen- 
tenas de cidades e vilas em toda a região, e deixando fazendeiros com dificuldades para fornecer alimento e água para gado (MARENGO; TORRES; ALVES, 2016). Ademais, desde 2014 o Sudeste do Brasil está enfrentando uma das secas mais graves em décadas causada por uma combinação de falta de chuvas e temperaturas mais elevadas. A escassez de água e crise hídrica tem afetado a população e as economias locais da região economicamente mais importante do país (NOBRE et al., 2016).

$\mathrm{O}$ crescimento populacional e econômico forçam os limites dos recursos hídricos mundiais (WORLD BANK, 2016). Há um crescente reconhecimento de que o mundo enfrenta uma crise hídrica que, se não for controlada, vai comprometer o desenvolvimento humano e econômico (UNDP, 2006; WORLD BANK, 2016). De acordo com a publicação do Fórum Econômico Mundial (WEF, 2016), a crise hídrica é um risco global que tem sido destaque nos últimos cinco anos. Categorizada como um risco social, (apesar de se relacionar mutuamente com o ambiente e a sociedade) a crise hídrica representa um declínio significativo na qualidade e quantidade de água disponível, resultando em efeitos nocivos à saúde humana e, ou, atividade econômica. Apesar dos esforços, essa crise continua sendo um distúrbio social, e particularmente, uma preocupação especial para o mercado, visto que a água é um insumo fundamental em muitas indústrias, produtos agrícolas e produção de energia (WEF, 2016).

\section{8 ÁGUA E INOVAÇÃO TECNOLÓGICA}

Dada a importância da inovação na transição para a sustentabilidade (FAO, 2014), este tópico resgata algumas considerações a respeito de tecnologias e práticas inovadoras, reforçando sua natureza evolutiva mediante a contínua necessidade de aperfeiçoamento. A mudança tecnológica é reconhecida como um dos principais motores do crescimento a longo prazo (UNIDO, 2015) e uma melhor gestão dos recursos hídricos exige melhores tecnologias hídricas (OECD, 2015) cujas alternativas tecnológicas já encontram-se disponíveis para os mais variados setores.

As atuais demandas da agricultura sobre os recursos hídricos mundiais são insustentáveis. O uso ineficiente da água para a produção agrícola esgota aquíferos, reduz o fluxo dos rios, degrada babitats, e causou a salinização em $20 \%$ da área 
irrigada global. Por dia, são utilizados 7,4 trilhões de litros de água para irrigação. Contudo, uma agricultura sustentável pode ser alcançada pela contínua adaptação, inovação e melhoria de estratégias, políticas e tecnologias, a fim de apoiar as mulheres e homens que ali trabalham, para maximizar a produtividade e produção, e para minimizar a pegada ambiental da agricultura (FAO, 2014).

O atual padrão tecnológico do setor energético é intensivo em emissão de gás carbônico $\left(\mathrm{CO}_{2}\right)$. Os governos podem contribuir para popularizar tecnologias de eficiência energética e fomentar a utilização de fontes de energia renovável, como a energia solar, que se destacou no segmento. Além disso, ações de monitorização e verificação são fundamentais para alcançar as economias de energia alvejadas (WEO, 2012). O Brasil possui um enorme potencial para a geração de energia hidroelétrica e tecnologia sofisticada disponível, fatores que contribuem para tornar essa energia uma opção favorável para a economia brasileira (OECD, 2015).

No caso das indústrias, há uma tendência natural das organizações buscarem a eficiência na utilização dos recursos. Empresários tendem a maximizar os lucros por meio da redução do uso de insumos mediante inovações de processo ou produtos. Espera-se para as próximas décadas que inovações, como a Internet móvel, a Internet das coisas e computação em nuvem, iniciem uma revolução dos processos de produção e melhorem os padrões de vida, particularmente em países em desenvolvimento (UNIDO, 2015).

As inovações no setor hídrico são altamente diversificadas. Por um lado, as novas tecnologias podem melhorar os métodos e processos existentes e torná-los mais eficientes e de baixo custo. Por outro lado, rupturas tecnológicas podem alterar fundamentalmente a forma como a água é utilizada. Estas implicações precisam ser melhor compreendidas para que medidas apropriadas possam ser tomadas a nível político (WWAP, 2016). Além do mais, é necessário enfrentar o desafio da difusão tecnológica, visto que muitas inovações são desenvolvidas em resposta à necessidade dos países desenvolvidos. Isso significa que tais tecnologias podem ser caras, utilizarem recursos não disponíveis em outros países ou serem projetadas para solucionar problemas específicos, não relevantes em escala global (BOELEE, 2011). Neste contexto, políticas governamentais precisam estar preparadas para assegurar a capacidade necessária para a criação e difusão de inovações relacionadas com os 
recursos hídricos contribuindo, assim, para a melhoria contínua da gestão das águas, proporcionando benefícios relacionados ao desenvolvimento econômico e geração de empregos (WWAP, 2016).

O Brasil atentou-se para a importância do papel da tecnologia ao integrar os Sistemas de Informação a gestão dos recursos hídricos, mediante a inserção de tópicos relativos à legislação vigente. Um exemplo é o Sistema Nacional de Informações sobre o Saneamento - SNIS, que foi idealizado em 1994, mediante disposições do Programa de Modernização do Setor de Saneamento - PMSS, e, desde então, vem se aperfeiçoando continuamente. Em 2007, a Lei $n^{\circ}$ 11.445/2007, que estabelece as Diretrizes Nacionais para o Saneamento Básico, institui no artigo 53 o Sistema Nacional de Informações em Saneamento Básico - SINISA (BRASIL, 2007), um novo sistema que seguramente incorpora o atual SNIS, vinculando-o ao Ministério das Cidades. O sistema reúne informações e indicadores sobre a prestação dos serviços de água, esgotos e manejo de resíduos sólidos provenientes dos prestadores que operam no Brasil, organizando-se em dois módulos, um sobre os serviços de água e esgotos (AE) e outro sobre os serviços de manejo de resíduos sólidos (RS). Os objetivos incluem: o planejamento e execução de políticas públicas; a orientação da aplicação de recursos; o conhecimento e avaliação do setor saneamento; a avaliação de desempenho dos serviços; o aperfeiçoamento da gestão; a orientação de atividades regulatórias e de fiscalização; e o exercício do controle social.

As informações referentes à $\mathrm{AE}$ provêm das instituições responsáveis pela prestação dos serviços de água e esgotos, tais como companhias estaduais, autarquias ou empresas municipais, departamentos municipais e empresas privadas. De acordo com a última coleta de dados, 84 indicadores referentes à prestação dos serviços de água e esgotos, de caráter operacional, financeiro e de qualidade dos serviços prestados foram calculados. Os dados são disponibilizados gratuitamente pelo site, fato que torna o SNIS o maior e mais importante sistema de informações do setor saneamento no Brasil (SISTEMA NACIONAL DE INFORMAÇÕES SOBRE SANEAMENTO, 2016).

\section{9 ÁGUA E PERSPECTIVAS}

Os Relatórios de Desenvolvimento Mundial da Água (WWAP, 2009; 2012) observam como as diversas crises globais relatadas recentemente - mudanças cli- 
máticas, energia, segurança alimentar, recessão econômica e turbulência financeira - estão relacionadas entre si e impactam sobre os recursos hídricos. Os relatórios ressalvam que a água desempenha um papel em todos os setores da economia e o aumento da demanda humana por esse recurso intensifica a concorrência entre setores consumidores, expondo a escassez de água (FAO, 2012).

Esse mesmo documento aponta que há uma percepção generalizada de que a água está se tornando escassa, como resultado de tendências que são, em certa medida, especialmente relacionadas ao crescimento populacional e o consequente aumento da demanda de água para produção de alimentos e usos domésticos, industriais e municipais (FAO, 2012).

De acordo com os resultados da Revisão de 2015 das Perspectivas da População Mundial (UN DESA, 2015), a população mundial atingiu 7,3 bilhões, em meados de 2015, o que implica o crescimento de um bilhão de pessoas nos últimos 12 anos. Constata-se que a população mundial continua a crescer, embora mais lentamente do que no passado recente. As projeções indicam que a população mundial irá aumentar em mais de um bilhão de pessoas nos próximos 15 anos, chegando a 8,5 bilhões em 2030, e aumentar ainda mais, para 9,7 bilhões em 2050 e 11,2 bilhões em 2100 .

Esse crescimento populacional encontra limitações que, apesar dos avanços, ainda se fazem presentes, como o acesso à água potável e saneamento, considerados pilares da saúde humana e bem-estar e essência do desenvolvimento sustentável. Por essa razão, as Nações Unidas inseriram entre os Objetivos do Desenvolvimento Sustentável (ODS) a meta de "Assegurar a disponibilidade e gestão sustentável da água e saneamento para todos", como um dos 17 objetivos para a agenda de 2030 (UNDP, 2015), reafirmando o compromisso em relação ao direito humano à água potável e ao saneamento.

Para garantir o cumprimento dessas metas até 2030, exige-se: investimento em infraestrutura e instalações sanitárias adequadas; incentivo à higiene; proteção e restauração de ecossistemas relacionados à água; e maior cooperação internacional (UNDP, 2016).

Todavia, está será uma tarefa árdua frente às perspectivas ambientais para 2050. Segundo a publicação da Organisation for Economic Co-Operation and De- 
velopment - OECD (2012), estima-se que 3,9 bilhões de pessoas irão conviver com o estresse hídrico severo. A demanda por água é projetada para aumentar em 55\% a nível mundial entre 2000 e 2050. O aumento virá principalmente da indústria $(+400 \%)$, energia elétrica $(+140 \%)$ e uso doméstico $(+130 \%)$. Em face dessas demandas concorrentes, haverá pouco espaço para o crescimento da irrigação. Ainda, tem-se os lençóis freáticos que estão sendo explorados a taxas superiores à capacidade de reabastecimento e estão se tornando cada vez mais poluídos. A taxa de retirada mais do que duplicou entre 1960 e 2000, atingindo mais de $280 \mathrm{~km}^{3}$ por ano.

No que se refere à qualidade dos recursos hídricos, o relatório indica uma melhoria contínua da eficiência na agricultura e do tratamento de águas residuais o que deve estabilizar e recuperar a qualidade das águas superficiais e subterrâneas na maioria dos países da OECD. Entretanto, para os demais países, assume-se que a deterioração da qualidade hídrica nas próximas décadas irá fomentar a eutrofização, perda de biodiversidade, doenças, incluindo a preocupação emergente com os micro poluentes (medicamentos, cosméticos, produtos de limpeza e resíduos biocidas). Por fim, inundações e secas se tornarão eventos cada vez mais comuns, mais graves e menos previsíveis. Estima-se que o número de pessoas em risco de inundações deverá aumentar dos atuais 1,2 bilhões para cerca de 1,6 bilhões em 2050 (OECD, 2012). Com base nessas projeções, é possível compreender que iniciativas devem ser tomadas para mitigar os impactos sobre os recursos hídricos.

\section{CONSIDERAÇÕES FINAIS}

Constatou-se que a água se inter-relaciona de forma dinâmica com diferentes questões estratégicas, tais como segurança alimentar, matriz energética, crescimento econômico, saneamento e sustentabilidade. As principais conclusões a reter podem ser sumarizadas de acordo com a estrutura analítica da revisão.

A primeira apreciação conduz a relevância da água no tocante à produção de alimentos. Constatou-se que a segurança alimentar está intrinsecamente ligada à disponibilidade dos recursos hídricos. Todavia, o setor que já se destaca mundialmente como o principal responsável pelas retiradas de água enfrentará grandes de- 
safios para suprir as crescentes demandas e os novos padrões alimentares. Por esta razão, buscar-se-á alcançar uma agricultura mais sustentável.

Chama-se a atenção também para o fato de que a água está intimamente ligada à geração de energia. Neste contexto, o aumento da eficiência do uso da água na produção energética é essencial, assim como uma gestão conjunta dos recursos hídricos e energéticos, a fim de suprir as crescentes demandas por esses recursos.

Analisando-se a abordagem industrial foi possível concluir que o setor investe em tecnologias objetivando a redução dos custos de produção, o que indiretamente impacta positivamente sobre o consumo de água. Todavia, a maior preocupação concerne à água residual cujo potencial de poluição pode ser um agravante, se não houver tratamento adequado.

Sobre o aspecto humano, o acesso a fontes de água potável e serviços de saneamento adequados constituíram as principais metas do ODM. Os resultados indicaram que o acesso à água potável foi satisfatório, porém a meta do saneamento não foi atingida. Ainda que melhorias tenham sido alcançadas, a universalização desses direitos fundamentais ainda representa um problema a ser solucionado.

Frente ao crescimento populacional, a industrialização, a geração de energia e a produção agropecuária são pressionadas devido à elevação do consumo. Portanto, a quantidade total de recursos hídricos exigidos para suprir tais demandas é crescente, sobressaindo a vazão retirada para uso agrícola.

Contudo, o fluxo hídrico ambiental também deve ser considerado neste cálculo. A água é provedora de serviços ecossistêmicos e a conservação dos ecossistemas é essencial para a manutenção do ciclo hidrológico, sendo a única garantia de disponibilidade a longo prazo.

Este é um ponto fundamental reforçado pela escassez que ameaça a sustentabilidade hídrica. A competição por água entre os usuários e entre os setores da sociedade vem desenhando a crise hídrica, que já se configura como um risco global e uma ameaça para o mercado.

Entretanto, alternativas tecnológicas eficientes e eficazes para a gestão das águas já encontram-se disponíveis, tais como modelagem, sistemas de informação ambiental, ferramentas de simulação e outras inovações tecnológicas computacionais, que permitem o gerenciamento, mediante o compartilhamento de dados, monitoramento e avaliação de riscos. 
Finalmente, as perspectivas apontam para a tendência de correlacionar a crise hídrica aos outros eventos críticos globais, como as mudanças climáticas, por exemplo. Assume-se também que o crescimento populacional e o incremento da demanda de água irão pressionar a atividade agrícola a manter ou até mesmo reduzir a vazão retirada. Além disso, os ODS renovam as aspirações de atender as necessidades de acesso à água potável e saneamento para todos.

\section{REFERÊNCIAS}

AGÊNCIA NACIONAL DE ÁGUAS - ANA. Conjuntura dos recursos hídricos no Brasil: 2013. Brasília: ANA, 2013. 432 p.

AGÊNCIA NACIONAL DE ÁGUAS - ANA. Conjuntura dos recursos hídricos: informe 2015. Brasília: ANA, 2015. 88 p.

BOELEE, E. Ecosystems for water and food security. Nairobi: UNEP, 2011. 194 p.

BRASIL. MINISTÉRIO DE MINAS E ENERGIA - MME. Plano Nacional de Energia 2030. Brasília: MME/EPE, 2007. 210 p.

BRASIL. Lei $\mathrm{n}^{0} 11.445$, de 05 de janeiro de 2007. Estabelece diretrizes nacionais para o saneamento básico; altera as Leis n ${ }^{0}$ 6.766, de 19 de dezembro de 1979, 8.036, de 11 de maio de 1990, 8.666, de 21 de junho de 1993, 8.987, de 13 de fevereiro de 1995; revoga a Lei n ${ }^{0} 6.528$, de 11 de maio de 1978; e dá outras providências. Diário Oficial da União, Brasília, 11 jan. 2007.

EMPRESA DE PESQUISA ENERGÉTICA - EPE. Balanço Energético Nacional 2015: Ano base 2014. Rio de Janeiro: EPE, 2015. 292 p.

FOOD AND AGRICULTURE ORGANIZATION OF THE UNITED NATIONS - FAO. Building a common vision for sustainable food and agriculture: principles and approaches. Rome: FAO, 2014. 56 p. 
FOOD AND AGRICULTURE ORGANIZATION OF THE UNITED NATIONS - FAO. Coping with water scarcity; an action framework for agriculture and food security. Rome: FAO, 2012. 100 p.

FOOD AND AGRICULTURE ORGANIZATION OF THE UNITED NATIONS - FAO. Information system on water and agriculture - AQUASTAT. Rome: FAO, 2016. Disponível em: <http://www.fao.org/nr/water/aquastat/water_use/index.stm > . Acesso em: 24 mar. 2016.

FOOD AND AGRICULTURE ORGANIZATION OF THE UNITED NATIONS - FAO. The state of the world's land and water resources for food and agriculture (SOLAW): managing systems at risk. Rome: Food and Agriculture Organization of the United Nations, 2011. 308 p.

FUNDO DAS NAÇÕES UNIDAS PARA A INFÂNCIA - UNICEF. 25 years progress on sanitation and drinking water: 2015 update and MDG assessment. New York: UNICEF, 2015. $90 \mathrm{p}$.

GRAFTON, Q. R. et al. Global water: issues and insights. Camberra: ANU Press, 2014. 248 p.

INTERNATIONAL ENERGY AGENCY - IEA. World Energ y Outlook 2012: Executive summary. France: OECD/IEA, 2012. 12 p.

MARENGO, J. A.; TORRES, R. R.; ALVES, L. M. Drought in Northeast Brazil - past, present, and future. Theoretical and Applied Climatology, Vienna, v. 124, n. 3-4, p. 1-12, 2016. Disponível em: < http://ink.springer.com/article/10.1007/s00704-0161840-8> . Acesso em: 09 jul. 2016.

MINISTÉRIO DA AGRICULTURA, PECUÁRIA E ABASTECIMENTO - MAPA. Projeções do agronegócio: Brasil 2015/16 a 2025/26 Projeções de Longo Prazo. Brasília: MAPA, 2016. $138 \mathrm{p}$. 
NOBRE, C. A.; MARENGO, J. A.; SElUCHI, M. E.; CUARTAS, L. A.; ALVES, L. M. Some characteristics and impacts of the drought and water crisis in southeastern Brazil during 2014 and 2015. Journal of Water Resource and Protection, Irvine, v. 8, n. 2, p. 252-262, Feb. 2016. Disponível em: < http://dx.doi.org/10.4236/ jwarp.2016.82022>. Acesso em: 06 jul. 2016.

ODMBrasil. O Brasil e os ODM. [S.l.:s.n.], 2016. Disponível em: < http://www. odmbrasil.gov.br/o-brasil-e-os-odm > . Acesso em: 20 jun. 2016.

ORGANISATION FOR ECONOMIC CO-OPERATION AND DEVELOPMENT - OECD/ FOOD AND AGRICULTURE ORGANIZATION OF THE UNITED NATIONS - FAO. OECD-FAO Agricultural Outlook 2015. Paris: OECD Publishing, 2015. 148 p.

ORGANISATION FOR ECONOMIC CO-OPERATION AND DEVELOPMENT - OECD. OECD Environmental Outlook to 2050: the consequences of inaction. Paris: OECD Publishing, 2012. 349 p.

OECD. Water Resources Governance in Brazil. Paris: OECD Publishing, 2015. 286 p.

PAUTASSO, M. Ten Simple Rules for Writing a Literature Review. PLoS Computational Biology. Cambridge, v. 9, n. 7, p. 1-4, Jul. 2013. Disponível em: <http://dx.doi. org/10.1371/journal.pcbi.1003149>. Acesso em: 05 maio 2016.

SISTEMA NACIONAL DE INFORMAÇÕES SOBRE SANEAMENTO - SNIS. Disponível em: < http://www.snis.gov.br/> . Acesso em: 23 mar. 2016.

UN WATER. Coping with water scarcity: challenge of the twenty-first century. New York: UN Water, 2007. 29 p.

UNITED NATIONS DEVELOPMENT PROGRAMME - UNDP. Human development report 2006: beyond scarcity: power, poverty and the global water crisis. New York: UNDP, 2006. 440 p. 
UNITED NATIONS DEVELOPMENT PROGRAMME-UNDP. Sustainable development goals. New York: UNDP, 2015. 21 p.

UNITED NATIONS DEVELOPMENT PROGRAMME - UNDP. UNDP support to the implementation of sustainable development goal 6: sustainable management of water and sanitation. New York: UNDP, 2016. 12 p.

UNITED NATIONS DEPARTMENT OF ECONOMIC AND SOCIAL AFFAIRS - UN DESA. Population division world population prospects: the 2015 revision, key findings and advance tables. New York: UN-DESA, 2015. 66 p.

UNITED NATIONS. The Millennium Development Goals Report 2015. New York: $\mathrm{UN}, 2015.75 \mathrm{p}$.

UNITED NATIONS INDUSTRIAL DEVELOPMENT ORGANIZATION - UNIDO. Industrial Development Report 2016: the role of technology and innovation in inclusive and sustainable industrial development. Vienna: UNIDO, 2015. 286 p.

WINTGENS, T.; LI, Y.; KAZNER, C. Water Resources and Industry. Water Resources and Industry, Maryland Heights, Mar/June. 2013. Disponível em: < http://www. sciencedirect.com/science/article/pii/S2212371713000358>. Acesso em: 15 jun. 2016.

WORLD BANK. World development report 2016: digital dividends overview. Washington: World Bank Group, 2016. 359 p.

WORLD ECONOMIC FORUM - WEF. The global risks report 2016: $11^{\text {th }}$ ed. Geneva: WEF, 2016. 103 p.

WORLD WATER ASSESSMENT PROGRAMME - WWAP. The United Nations World Water Development Report 3: water in a changing world. Paris: UNESCO, 2009. $349 \mathrm{p}$. 
WORLD WATER ASSESSMENT PROGRAMME - WWAP. The United Nations World

Water Development Report 4: managing water under uncertainty and risk: volume 1. Paris: UNESCO, 2012. 407 p.

WORLD WATER ASSESSMENT PROGRAMME - WWAP. The United Nations World Water Development Report 2014: water and energy. Paris: UNESCO, 2014. 230 p.

WORLD WATER ASSESSMENT PROGRAMME - WWAP. The United Nations World Water Development Report 2015: water for a sustainable world. Paris: UNESCO, 2015. 139 p.

WORLD WATER ASSESSMENT PROGRAMME - WWAP. The United Nations World Water Development Report 2016: water and jobs. Paris: UNESCO, 2016. 164 p.

Recebido em: 15/10/2016 Aceito em: 11/06/2017 